\title{
Research on Decreasing Interest in Mandarin Studies in Mainland China
}

\author{
Huiqiang Zheng \\ Xiamen University, China \\ Email: huiqiangz@gmail.com
}

\begin{abstract}
This paper is aiming at exploring possible reasons for decreasing interest in Mandarin studies for high school students. We summarize characteristics of high school students from three perspectives: observation, memory, thinking ability. According to some report, interest in Mandarin studies at Longxian High School is waning in recent years. In this paper, we find the reasons for the decreasing interest in Mandarin are as follows: negative emotion and deficient knowledge of teachers, increasing gap between teachers and students caused by inadequate communication. In reading classes, problems lie in traditional cramming way of teaching, exam-oriented and overemphasis on scores, and monotonous way of class organization. To solve these problems, we provide suggestions on strategies of organizing Chinese classes using performing and competition ways. In writing class, topics are too far away from students' daily lives, and exams are overemphasized too. Positive feedbacks from teachers are inadequate to maintain the situational interest of students. Recommendations are proposed on preparation before class, timely positive feedbacks in the essay, and adjustment in evaluation ways.
\end{abstract}

Index Terms - declination of interest, situational interest, instructing method, class organization

According to the survey at Longxian High School, average academic scores for Mandarin studies are declining sharply in recent years. More and more students cannot perform well in Chinese subject in College Entrance Exams. Based on the investigation in Longxian High School, which is located in the northwestern part of Mainland China, we find that students' performances in Chinese classes are far from satisfaction and the existing problems in Chinese classes are pertinent to the waning interest. The paper is based on the assumption that interest would positively promote learning. After observing Chinese classes for half a year and interviewing with local students, we provide practical suggestions to solve problems in reading and writing. According to some previous research, high school students are being in a special stage, which is characterized by the following features comparing with other stages.

Characteristics in observing ability: Previous research (Zhang, 1999) shows that high school students are in a stage of independent thinking. One of the characteristics of observation ability is that high school students are having definite purpose in observation with increased duration. Secondly; observation ability is developed into a stage with enhanced precision in details and accurate judgments in essence. Thirdly, high school students possess better generality and relatively mature minds.

Characteristics in memory: Memories of high school students are reaching a peak in the perspectives of conscious memory and comprehensive memory. Although the amount of rote memory is not as good as middle school students, the quality and quantity of memory in general meaning are two times of middle school students, and four times of elementary school children (Guo, 2001).

Characteristics in thinking: Senior students are mature both physically and mentally, and their thinking modes are changed from the experienced to theoretical ones. Logical thinking and critical thinking are developed in full bloom. Transference and creativity are enhanced at the same time. High school students are adults-to-be and sometimes are one-sided and easily frustrated.

As mentioned above, instructing methods should be designed adapting to the characteristics of high school students. Tasks should be challenging enough to raise the interest and curiosity of students.

\section{RESEARCH ON THE REASONS FOR DECREASING INTEREST OF MANDARIN STUDIES}

\section{A. Problems of Teachers}

Negative emotion of teachers: Emotion of teachers will influence the students and the atmosphere in the class. Negative one will worsen the boring class. Prejudice toward good students and overemphasis on scores will also have bad effect on sensitive students.

Deficiency in knowledge: Some of the teachers are not knowledgeable enough to comprehend Chinese language with some other disciplines such as history, politics, culture, etc. to raise the interest of students. Others are unfamiliar with new facilities and technologies which are connected to update resources.

Lack of communication and interaction: Without passionate and active emotion to influence students, teachers arrange the class in a predesigned way and in strict conformity to guidelines. These teachers ignore the characteristics of high school students and act improperly by regulating them. The students are not stirred and the interest of learning is 
damaged. Another result caused by lacking communication is the increasing gaps between students and teachers. According to the survey, one of the qualities of a popular teacher is considerate, which means the teacher should be easy to communicate with and sometimes can be friends of the students.

\section{B. Problems in Reading Classes}

Traditional cramming way of instruction. In this method, the final goal of teaching is the only specific answer instead of process of thinking and way of solving problems. At Longxian High school, the survey indicates that the most serious problem in Chinese teaching is the method of cramming. The primary reason is the old concept in curriculum. It is common at Longxian High school that the teacher is instructing without any interaction with students. The task of teachers is offering correct answers to questions without detailed explanation, and students are only expected to memorize the answers in notes. They are inhibited from active and critical thinking, so teachers are actually becoming the center of the class. The class is arranged in stiff model and taught in one way without adjusting to the different levels of students. The thinking ability is not enhanced and neither the literature proficiency in the learning process. As time goes by, the learning interest of students is decreasing and one third of the students in the survey admit that they are always distracted from class. Half of the students indicate the current Chinese course is boring and spiritless. On the other hand, $70 \%$ of the respondents are willing to participate in the class activities. Half of the students show preference to the class in which they can probe the problems by themselves through activities. Nearly one third of the students indicate the preference to group discussion and cooperation with classmates. High school students are adults who are independent thinkers and have strong self-consciousness, so they refused to be a recorder of the teachers' ideas.

Frequent exams and overemphasis on scores. As a result, Chinese classes become exam-oriented and classes are arranged under the guide of exams, putting aside the thinking ability and the language proficiency. On the other hand, students are frustrated by a series of informal exams, which are not reflecting their actual abilities in reading and writing. The goal of Chinese Class in high school should be measured in three dimensions, knowledge \& skills, process \& methods, emotion, attitude \& values. Too much emphasis on the final exam results leads to ignorance of the learning process, does no good to the language skills, and has bad influence on the passion and interest in Chinese studies.

Monotonous organization and dull teaching methods. Some of the teachers lead the class in a boring and impassionate way. As a result, inspiration of students is inactive and creativity is inhibited. Some of the teachers are inflexible and stick to one single way in teaching or limited themselves to teaching materials and reference books. Students are easily losing their interest when they can only learn to summarize reading materials in a duplicated way without making progress in writing and critical thinking. $62.3 \%$ of the respondents in the survey of Longxian High School attribute boring Chinese studies to monotonous teaching way. Classes are organized in dreary methods, from explaining new vocabulary to paragraph analysis, from inside meaning of one sentence to the summery of the whole paragraph. Teachers are tired of dreary instructing, while students are tired of the fixed way of learning. This kind of class is not interesting at all, not to mention inspiring and exciting students. However, some of the experienced teachers are adopting different methods in instructing, and it is rare that they can adjust and design according to different students and arrange the class in a delightful way.

In addition, reading materials especially texts written in ancient Chinese, according to the students, are the most difficult. $73.8 \%$ of the respondents in Longxian High School indicate negative attitude towards ancient Chinese materials. The requirements of reciting texts worsen the situation and result in the declining interest in Chinese learning.

Solutions: Lead the class in a flexible and diverse way. Chinese class are criticized as old topics and organized in hackneyed way without any novel elements. Admittedly, Chinese classes are not updating year after year unlike what scientific subjects do. The old mode in instructing Chinese classes should be changed adapting to new situations. Creative and suitable ways are encouraged. Firstly, performing way in drama unit is a good way to increase interest. During the time of preparation, students are collecting background information, try to understand the content and understand different characters in a drama. In addition, students are pushed to learn the subject by themselves.

Secondly, competition can be introduced in proper time. Teachers are responsible for the detailed grading criterion and divide the students into different groups.

Thirdly, story retelling can be implemented and combined with oral composition. For example, some texts written in ancient Chinese which are descriptive can be organized in this way.

\section{Problems in Writing Class}

Writing has been an important and difficult part of language proficiency in the stage of high school. Students are sick of writing articles in class.

The key reason why students are afraid of writing is that they are not confident in using the language, especially how to express themselves accurately and polish drab language. The improvement of writing is a long process which requires massive reading and long-term accumulation. It is a long process when students refine their taste, appreciate beautiful expressions and learn how to use them. Most of the respondents at Longxian High School do not form good habits of keeping diaries. Only one fifth of the students admit that they often keep diaries and jottings. Others feel blank when they are asked to write in class because of careless observation in life and no accumulation of essays.

Writing classes were exam-oriented too. A lot of restrictions are set on styles or contents, even the number of words in exams prevent students from putting imagination into full play. What students do in the exam is trying their best to 
guess the original intention of the topic and write as required, namely expository writing, argumentative writing or narrative paragraphs in a prosaic way. Teachers are putting overlade emphasis on exams, neglecting good inspiration in the casual essays.

The situational interest (Hidi, 1988 \& Kappy, 1989) which is defined as transitory state of the focused attention and the immediate feelings triggered by the situation, cannot be maintained (Mitchell, 1993) and transformed into individual interests (Hidi,2001) for the lack of encouragement and feedback. Most teachers only grade the composition rather than writing positive feedbacks, which frustrate students with low scores. Feedbacks from teachers play an important role in the transformation of long-term interest, which is called the evocative emotional reactions (Schraw, Flowerday \& Lehman, 2001).

Topics in exams are too far away from students' lives. In fact, prose is the favorite style for students at Longxian High School due to its beautiful language and fresh imaginative way of writing. Thus, students are actually not afraid of free writing, but they always fail to write the composition assigned by teachers. In a loose and comfortable atmosphere, students take delighted in choosing topics and writing in their own style. In a word, how to arouse the interest of students is the most important issue in the writing instruction.

Solution: In the first place, sufficient preparation before writing class. Sufficient preparation can be done in different ways and adjusted at times, such as discussion in groups, activities out of class, and oral practice. It can also be reading. Combination of reading and writing is beneficial for students to improve the writing ability. Reading relative materials and background information is proved to help increase the engagement (Mitchell, 1993, Schraw \& Stephen Lehman 2001) and encourage unconfident students to make an early start. As a result, writing after reading is a good way to maintain the interest of Chinese studies. On the other hand, discussion in class will comfort the students who are nervous to strengthen their sense of belonging so as to maintain the interest of studies (David, 1999).

In addition, positive feedback and timely encouragement are crucial for students in maintaining the interest even for a little progress or sparkles. Interest of learning needs to be intrigued and then maintained. Positive feedbacks from teachers are one of the ways to encourage students to dig out their potential and strengthen their sense of self-efficiency.

Finally, change of evaluation way is required. Integration of self-evaluation and group assessment will arouse the enthusiasm of students. Students are beneficial in discussion through learning from partner.

\section{SUMMARY}

Considering all of the problems in reading and writing classes we have found, teachers have huge potential to further improve their teaching skills, which means they can do much to increase the interest of students in Chinese studies by improving the instructing methods or diversifying the organization of class. High school students are in a special stage with characteristics in observation, memory, and thinking which we can take full advantage of to maintain the situational interest or change it into personal interest.

\section{REFERENCES}

[1] Chen, A., P.W. (2001). Situational interest in physical education: A function of learning task design. Research Quarterly for Exercise and Sport, 72,150-164.

[2] David A. Bergin. (1999). Influences on Classroom Interest, Educational Psychologist, 34, 87-98.

[3] Frick, R.W.(1992). Interestingness. Psychology, 83, 113-128.

[4] Gregory Schraw, and Stephen Lehman. (2001). Situational Interest: A Review of the Literature and Directions for Future Research, Educational Psychology Review, 13, 211-224.

[5] Mary Ainley. (2006): Connecting with Learning: Motivation, Affect and Cognition in Interest Processes. Educational Psychology Review, 18, 391-393.

[6] Gregory Schraw, Stephen Lehman. (2001). Situational Interest: A Review of the Literature and Directions for Future Research. Educational Psychology Review, 13, 23-25.

[7] Gregory Schraw, Terri Flowerday, and Stephen Lehman. (2001). Increasing Situational Interest in the Classroom. Educational Psychology Review, 13, 211-221

[8] Guo, Hengjie \& Huang, Xiting, (2001). Studies and implement of Psychology, Shanghai: Shanghai Education Press.

[9] Harp, S. f., Mayer, R. E. (1998). How seductive details do their damage: A theory of cognitive interest in science learning. Educational Psychology, 90, 414-434.

[10] Hidi. S. (1990). Interest and its contribution as a mental resource for leaning. Review of Educational Research, 60, 549-572.

[11] Hidi, S., Baird, W. (1986). Interestingness - A neglected variable in discourse processing. Cognitive Science, 10, 179-194.

[12] Hidi, S., Renninger, K.a., \& Krapp. A. (1992).The present state of interest research. In Erlbaum, Hillsdale (Eds.), The Role of Interest in learning and development. NJ, 433-466.

[13] Hidi, S., and Harachiewacz, J. M. (2001). Motivation the academically unmotivated: A critical issue for the 21 century. Review of Educational Research, 70,151-179.

[14] Li, Chuangxin. (2001).Innovative way of teaching Chinese, Beijing: Xueyuan Press.

[15] Lin, Chongde, Shen, Jiliang. Gu, Shenghua. Yan, min. (2001). Psychology of Chinese Teaching in Secondary School, Beijing: Beijing Press, Beijing Education Press.

[16] Mitchell. M. (1993). Situational Interest: Its multifaceted structure in the secondary school mathematics classroom. Educational Psychology, 85, 424-436.

[17] Schraw. G. (1998). Processing and recall differences among selective details. Educational Psychology, 90, 3-12. 
[18] Schraw. G. (1997).Situational interest in literary text. Contemporary Educational Psychology.22, 436-456.

[19] Wade, S. E., Boxton, W.M. \& Kelly, M.(1999). Using think-alouds to examine reader-test interest. Reaching Research Quarterly, 34, 194-216.

[20] Zemmerman, B.J. \& Kitsantas, A.(1997). Developmental phases in self-regulation: Shifting from process goals to outcome goals. Educational psychology, 89, 29-36.

[21] Zhang, Yongsheng. (1999). Educational Psychology, Shijiazhuang in China: Hebei Educational Press.

[22] Zhao, Houyu. (2003). The modern interpretation of Chinese Education. Beijing: Central Compilation \& Translation Press.

Huiqiang Zheng was born in Quanzhou, China in 1983. She is a Ph.D. candidate now in Chinese Department in Xiamen University. Her research interests are Language education, Culture Communication, Contrastive Linguistics, and Educational Psychology.

She was a full time lecturer teaching Chinese I/II and Chinese Culture in the University of Texas Pan-America from 2008 to 2009. She was part-time lecturer in Xiamen University in summer of 2004, 2005, 2007, spring of 2010.

Ms. Zheng is a member of the International Society for Chinese Language Teaching. 